\title{
GETTING A HANDLE ON DESIGNING FOR AVIONICS SOFTWARE SUPPORTABILITY AND MAINTAINABILITY
}

\author{
Charles P. Satterthwaite \\ Avionics Logistics Branch \\ Wright Laboratory \\ Wright Patterson AFB OH 45433-6543
}

\begin{abstract}
The engineering design issues of supportability and maintainability are expanded upon so that interested individuals can understand (1) how these issues impact a modern weapon system, (2) what impact the lack of concern for these issues is having on today's weapon systems, and (3) how these issues might be better considered and implemented in future weapon system designs.
\end{abstract}

\section{INTRODUCTION}

The planners of future applications for avionics software are frequently tasked with the issues of supportability and maintainability of this software. These issues are often treated as unique design issues which await break-through technologies for their implementation. Oftentimes they are shoved aside (or deprioritized) in preference of more concrete and understandable concepts. As a result, poor specifications for supporting and maintaining systems are generated, which are increasingly costly in terms of the weapon system's life-cycle.

This paper addresses those people involved in the acquisition, logistics, and use of avionics software by showing cases of avionics software supportability and maintainability and how to go about designing it. Section I is an introduction of the material in this paper. Section II defines supportability and maintainability. Section III gives an idealistic example of a strongly designed supportable and maintainable futuristic fighter. Section IV reviews the state of supportability and maintainability today. Section $\mathrm{V}$ examines the new field of Software Engineering and how it should be focused to impact designing for supportability and maintainability. Section VI reviews the engineering design process and how it can accommodate supportability and maintainability. Sections VII and VIII apply the engineering design process to software scenarios and show where supportability and maintainability should be considered in their designs. Section IX gives a brief summary of this paper.

\section{SUPPORTABILITY AND MAINTAINABILITY DEFINED}

Supportability (in the context of Avionics Software) is the provision of sophisticated equipment, special facilities, and detailed documentation in order to perform maintainability. Maintainability is the probability that a failed computer software configuration item (CSCI) can be repaired in a specified amount of time using a specified set of resources [4].

\section{AN IDEALISTIC EXAMPLE OF SUPPORTABLE AND MAINTAINABLE AVIONICS SOFTWARE}

Let's project ourselves into the year 2020 and pretend we have the management responsibility for the nation's latest ALL-ENGAGEMENT Fighter. This remarkable aircraft can fly in space or in close ground support, it is stealthy, and it has a new impulse propulsion system which greatly reduces its fuel requirements. It also has a fully integrated open system architecture enabled by 50 million lines of source code.

More remarkable than this system's hardware features and capabilities is the built-in design for system supportability and maintainability. The Fighter is accentuated with redundant, reconfigurable, and fault-tolerant software which provides a full mission software report following each sortie. The Fighter is also arranged so that it can be configured as a simulator with the capability of supporting any level of testing, including sub-system testing and fullup integrated testing (air or ground). Every level of this Fighter's life-cycle is linked by a network of interconnected media which enables precise and traceable documentation as well as on-line communication. The significance of this is that the software maintainer, the acquisition specialist, and the pilot have a perfect flow of information in which they can report problems, specify requirements, and train each other through a common media.

Upon close examination of the Fighter's software, we discover more amazing design features. First of all, there 
is $100 \%$ source code compatibility among the 300 embedded computers on the Fighter. These 300 embedded computers are written in Higher Order Language (Ada 2020) and are facilitated by two very compatible compilers. There are 1500 Software Modules which populate the Operational Flight Programs (OFPs) of the 300 embedded computers. Of these 1500 Modules, $40 \%$ (600 Modules) are common among the embedded computers and help encompass the Fighter's dynamically reconfigurable resources. Another useful design feature is the emphasis on reusable code. Thirty percent of the 1500 Modules (450 Modules) are static in nature and can be used over and over again between block cycle changes and between other aircraft.

Our final investigation is of the Fighter's Software Support Environment. There are two options available for those concerned with changing the Fighter's 300 OFPs. The first option is to use the Fighter's built-in capability, which is a pull-down avionics engineering workstation. Dynamic source code changes can be made directly on the aircraft, with the aircraft itself acting as the integrator and tester. This accommodates battlefield fixes allowing for quick response times and emergency repairs. The next option is the more formal option which is the Centralized Fleet System Support Facility (CFSSF) which is able to maintain any of the DoD's 3000 OFPs. In both options, the OFP Module Maintainer uses sophisticated engineering workstations which dynamically configure the required resources for a given change requirement; automatically documents any action; creates specialized testing for the changes; inquires the CFSSF archives for documentation and software related to the change requirement and displays this data on-line; and builds loadable OFPs.

Note that the originality of our ALL-ENGAGEMENT Fighter is that it has been emphasized in its design to be supportable and to be maintainable. This has not been the case with today's weapon systems whose supportability and maintainability have been developed in the middle of their life cycle and oftentimes after they have been transitioned to their support organizations.

\section{SUPPORTABLE AND MAINTAINABLE AVIONICS SOFTWARE TODAY}

Today's generation of weapon systems uses avionics software which is supported and which is maintained. But is this software supportable? and is it maintainable? The answer to these questions depends on what is considered acceptable by the owner of the weapon system. If the owner finds acceptable 18 month (or longer) block cycle turn-over times and increasingly costly avionics integrated support environments, then the answer to both is yes. But if the owner faces rapidly changing threat environments and shrinking budget constraints, the answer is clearly no.

Today's typical software support environment is the Avionics Integrated Support Facility (AISF) which is now being called the Centralized Software Support Activity (CSSA). A typical AISF can maintain 5 to 10 OFPs. Each OFP requires specialized support equipment, most of which is incompatible with the other OFPs' support equipment. Each OFP also requires specially trained people who are generally overloaded with the workload for that OFP [6].

The typical avionics software OFP should be reviewed as far as its maintainability. Of the 5 to 10 OFPs which are maintained in an AISF, each has its unique source code (usually assembler language) with unique support utilities such as compilers and linkers. In order to integrate two or more OFPs together, specialized software and hardware has to be developed allowing them to pass information. Other specialized processes include documentation, testing, configuration management, and training. Given our definition of maintainability and today's increasingly constrained AISFs, the probability is low that CSCIs can be repaired in a timely manner.

The situation facing today's avionics software maintenance organizations is that they will manage an increasing number of OFPs ( 20 and up) with the same or fewer resources. Given today's scenario of an increasing workload and with the same or fewer resources, previous design considerations for supportability and maintainability will be obsolete, if they aren't already [2],[3],[5],[6].

\section{APPLYING SOFTWARE ENGINEERING DISCIPLINE TO OBTAIN SUPPORTABLE AND MAINTAINABLE AVIONICS SOFTWARE}

As Software Engineering has been evolving, two camps have emerged as the champions for this new discipline. The first camp has been largely responsible for bringing Software Engineering where it is today. This is the Computer Science Camp. The Computer Science Community has effectively responded to the recent challenges of the "Age of Automation" which include an ever increasing appetite for software. The second camp is responsible for software as it is increasingly utilized in systems of every type. This camp is the Traditional Engineering Camp. Unfortunately, these camps have been less than cooperative. The Computer Science Camp desires Software Engineering to be a more creative and flexible discipline while the Traditional Engineering Camp would like to see Software Engineering stress standards which would enable software to be reliable, supportable, and maintainable for its complex systems. Objectively, Software Engineering 
should best serve both camps. It should be creative and flexible enough to respond to new challenges while also serving the existing system's requirements. The existing software requirements of today's Avionics Systems denand increasingly complex and repeatable solutions for mature weapon systems platforms. These systems are not easily receptive to new technologies because they have been independently developed with limited concerns to their long term support requirements. To add to the complexity of these systems is their diverse support environment requirements seen in the increasing demand for Avionics Integrated Support Facilities.

\section{THE ENGINEERING DESIGN PROCESS}

The design process is a systematic flow of developing an item of equipment that meets a predetermined product specification. The basic concept for any design process is a controlled approach to translating the product specification into a working system that fulfills the need of the user. While products of the design process can be anything imaginable, the basic design process, in theory, should be identical. The design process is a series of coordinated activities that form the basis for all activities necessary to produce the desired item. The design process must integrate the efforts of all engineering disciplines to ensure that the user's needs and requirements are met by the final product design [4].

In order for supportability and maintainability to be included in the design process, they must be carefully and completely specified along with the other constraints of the system.

\section{APPLYING THE PROCESS TO A SIMPLE SOFTWARE PROBLEM}

Let's consider the case where a simple software program is the product of the design process. The series of coordinated activities are those specified in MIL-STD-2167A [1] which include system requirements analysis and design, software requirements analysis, preliminary design, detailed design, coding and unit test, component integration and testing, item testing, and system integration and testing. Let's say this software runs a digital clock and displays the clock's output. In application of our design process, the system requirements analysis and design tells us we need an automated time system. The software requirements analysis tells us we need software to run a digital clock. The preliminary design lays out the functionality of software, its testing needs, and the components it will require. The detailed design specifies the software to the lowest level and plans for low level testing as well. Component integration and testing checks our low level design. Item testing checks out our complete software design. Finally we try our software out in its digital clock by performing a system integration and test by installing and running it [7]. Where in this process should we specify the desired level of supportability and maintainability? Since we want our software to meet a predetermined level of both supportability and maintainability, we must clearly lay out our requirements in the system requirements analysis and design.

\section{APPLYING THE PROCESS TO A COMPLEX AVIONICS PROBLEM}

Taking the same digital clock software, we will apply some requirements which will make it much more complicated. These include: (1) The software will be the basic timing logic for a modern fighter systems fire control computer operational flight program. (2) The software is to be modular and generic so that it can be used in multiple applications including other weapon systems. (3) The software will be field changeable in 24 hours or less. (4) The support environment for changing and testing this software will be totally commercial off-the-shelf (COTS) equipment. It would be foolish to handle these requirements anywhere but up front in our design process. It has been proven [7] that software support and maintenance account for $70 \%$ and more of the overall system life-cycle costs .

\section{SUMMARY}

Increasingly, the cost and time spent in developing and operating weapon systems is found in those systems' software. The majority of the software cost and time spent is in its maintenance and support. Without carefully specifying the requirements for supportability and maintainability during system requirements analysis and design, the ability and affordability of operating a weapon system becomes prohibitive. The engineering design process already exists. This process, when properly specified, will accommodate building supportability and maintainability as weapon system requirements. 


\section{REFERENCES}

[1] DOD-STD-2167A, Military Standard Defense System Software Development, 29 February 1988.

[2] Harris, R.L., "Laboratory Concepts in Avionics Software", IEEE/AIAA/NASA 9th Digital Avionics Systems Conference Proceedings, 15-18 October 1990, Virginia Beach VA.

[3] Harris,R.L.,Jackson,O., "Software Engineering Tools For Avionics Embedded Computer Resources", IEEE/AIAA National Aerospace Electronics Conference Proceedings, 21-25 May 1990, Dayton OH.

[4] Jones,J.V., Engineering Design Reliability, Maintainability, Testability, TAB Books Inc., Blue Ridge Summit, PA, 1988.

[5] Morris,D.M., "Avionics Operational Flight Program Software Supportability", IEEE/AIAA/NASA 9th Digital Avionics Systems Conference Proceedings, 15-18 October 1990, Virginia Beach VA.

[6] Satterthwaite,C.P., Maintaining An Operational Flight Program (OFP), Air Force Technical Memorandum WLTM-91-123, Wright-Patterson AFB, OH, 1991.

[7] Computer Resource Acquisition Course, "Course Materials Volume I and II", System Acquisiton School, 6575TH School Squadron, Air Force Systems Command, Brooks AFB, TX, December 1991. 